\title{
Análisis sintáctico funcional: principios, perspectivas y casos
}

\author{
Functional Syntactic Analysis: Principles, Perspectives and Cases
}

\author{
Claudio Pinuer Rodríguez
}

Universidad de Concepción, Departamento de Español, Concepción, Chile. e-mail:cpinuer@udec.cl

\begin{abstract}
En este trabajo se presenta una revisión de los principios epistemológicos, bases teóricas y metodología de trabajo de la sintaxis funcional. Para ello, se examina una bibliografía representativa de las principales escuelas funcionalistas: particularmente, del funcionalismo norteamericano y europeo español. También, se incluye una evaluación de tres tópicos gramaticales, descritos desde una perspectiva funcional, a través de lo cual se ilustra la metodología pragmagramatical que considera el estudio del nivel sintáctico, semántico e informativo. Entre los resultados más importantes se demuestra la necesidad de seguir avanzando en el diseño de métodos de análisis empírico de fenómenos lingüísticos condicionados pragmáticamente. Como, asimismo, que la metodología debe incorporar descriptores lingüísticos y pragmáticos, con énfasis en la interacción entre ambos estratos.
\end{abstract}

Palabras clave: funcionalismo, sintaxis, pragmática.

In this paper a revision of the epistemological principles, theoretical and methodological bases for a work on functional syntax is presented. For this purpose, a representative bibliography of the main functional schools is examined, mainly the North American functionalism as well as the European-Spanish one. It is also included an evaluation of three grammatical topics which are described from a functional perspective and illustrated through a pragmatic-grammatical methodology that takes into account the syntactic, semantic and informative level. The most important results show the necessity of continuing advancing in the design of methods of empirical analysis for linguistic phenomena pragmatically conditioned. At the same time, the methodology used must include linguistic and pragmatic descriptors with emphasis on the interaction between them.

Key words: functionalism, syntax, pragmatics.

\section{LA PERSPECTIVA FUNCIONAL}

En 1978, Simon C. Dik propuso un nuevo modelo lingüístico que denominó Gramática Funcional (GF), en el que se definieron las tres grandes líneas que iban a guiar la investigación posterior del paradigma: la exclusión de las transformaciones, la definición de un único nivel de representación y la negación de la autonomía de la sintaxis. A partir de este momento, la GF ha progresado para cumplir los criterios de validez pragmática (no debe haber contradicción con los usos auténticos del lenguaje), psicológica (la teoría no debe contravenir, por ejemplo, los avances que ha logrado la psicolingüística en la descripción de la adquisición de la lengua) y tipológica (los resultados deben tener valor interlingüístico), definidos por el mismo autor en 1989. En esencia, la GF ha incorporado un modelo clausal multicapa, ha iniciado una aproximación a los problemas discursivos, se ha implicado en cuestiones de representación del conocimiento y se ha orientado hacia problemas computacionales (Christopher Butler et al. 1999).

El análisis multicapa se sustenta en el principio de que la cláusula (nexus) tiene tres niveles sintácticos de organización: el núcleo, instanciado por el verbo; el centro, expresado por el núcleo más los complementos argumentales, y la periferia, donde se sitúan los complementos no argumentales.

Esta división del nexus destaca la función del verbo como funtivo nuclear, en torno al cual se selecciona y organiza el resto de los componentes de acuerdo con su rango argumental. Los funtivos que ostentan jerarquía argumental son esenciales en la predicación del verbo, pues codifican, por una parte, sus valencias combinatorias y, por otra, identifican las entidades incluidas por el hablante en el evento o suceso comunicado. Estas entidades son argumentos, por lo cual las magnitudes funcionales que los instancian son complementos argumentales.

El adjetivo funcional se encuentra en la denominación de muchas teorías lingüísticas y falta en otras que tienen una orientación similar; por esto, resulta conveniente precisar algunos criterios que definen el enfoque funcional. Veremos dos.

El primer criterio para considerar funcional una teoría es la orientación general del modelo, en el sentido de si atiende o no al fin primordial del lenguaje articulado humano, que es la interacción social por medio de la comunicación, teniendo en cuenta "sus condicionantes y mediatizaciones" (César Hernández 1996: 23).

El segundo criterio viene dado por lo que Kuno (1980) denominó el control externo de la sintaxis: los modelos de corte sintacticista, como la Gramática Léxica-Funcional, en los que el componente semántico-pragmático es más bien periférico, no se consideran funcionales, pues atribuyen autonomía al componente sintáctico. Siguiendo con este punto, las teorías funcionales del lenguaje prestan especial atención a las funciones sintácticas, semánticas y pragmáticas y, sobre todo, a la relación entre éstas.

También contribuye a la tarea de desentrañar la esencia del funcionalismo, reconocer aquellos puntos en que éste se ha deslindado de teorías próximas, como el estructuralismo. Según Givón (1995), la tradición funcional ha tomado distancia de los tres dogmas estructurales de mayor tradición: el dogma de la arbitrariedad, según el cual el significante del signo lingüístico es arbitrario respecto de su correlato mental (el significado); el dogma de la idealización, que establece que el sistema ideal, la lengua, es el objeto único y total de estudio de los lingüistas, excluyendo el habla, y el dogma de la incompatibilidad temporal, 
que estipula que la dimensión sincrónica y diacrónica de la lengua deben estudiarse por separado.

En la misma línea, Givón ha establecido el catálogo de temas a tratar en una sintaxis que, además de ser funcional, tenga la pretensión de contar con adecuación interlingüística. Este repertorio ha sido presentado con originalidad y autocrítica al reconocerse que hay aspectos del lenguaje que se acomodan más fácilmente que otros a un enfoque tipológico discursivo y resultan, por tanto, más fructíferos para un estudio funcional. En concreto, estos temas son: las funciones sintácticas primarias; la definición y la referencia; la anáfora y la catáfora; la flexión verbal; la negación; la voz y la topicalización; la focalización y la relativización; los actos de habla; la conexión, y la subordinación clausal.

Por otra parte, Michael Halliday, creador de la Gramática Sistémica, sostuvo que una gramática paradigmática (funcional) debe ofrecer una explicación del propósito con el que se usa el lenguaje, al mismo tiempo que construir una teoría más amplia del comportamiento humano asociada a la pragmática o a la sociolingüística. La precisión de Halliday es, desde una perspectiva historiográfica, muy esclarecedora, pues las ideas funcionales son foráneas a la lingüística, como ha destacado el autor (2005: 236): "Functional theories of language came originally from outside linguistics".

Para la tradición funcionalista española, representada en las escuelas de Oviedo (Emilio Alarcos, Josefina Martínez, José Antonio Martínez, Alfredo Alvarez, César Hernández), en la escuela de Santiago de Compostela (Guillermo Rojo, Milagros Fernández, Jesús Pena y Tomás Jiménez Juliá) y en la escuela de León (Salvador Gutiérrez, Bonifacio Rodríguez, Manuel Iglesias, Mercedes Rueda); las asunciones teóricas comunes a las diversas orientaciones son (Angel López García 2000: 16).

- Principio de inmanencia, según el cual se rehúyen las explicaciones lógicas o psicológicas.

- La lengua como instrumento de comunicación, lo cual abre el camino a las consideraciones situacionales.

- Funcionalismo realista: pasado el primer rigorismo formal, las formas se consideran en su imbricación con la realidad.

- Doble articulación: el signo se descompone en dos niveles al menos, el fonológico y el gramatical.

- Principio de economía, tanto en sincronía como en diacronía.

- Cada lengua se considera como una red formal específica proyectada sobre el mundo sustancial.

- Las funciones son los polos de una relación.

- Criterios posicionales y conmutacionales en el análisis.

- Tendencia a asignar una categoría a una función.

- Principio de la transposición, por la que una secuencia desempeña funciones distintas de la que resulta característica de su categoría nuclear.

Para el funcionalismo, las lenguas son objetos funcionales de lo que se sigue, de acuerdo con Salvador Gutiérrez (1997c: 469), que: "no existe mejor descripción de un objeto funcional que el que toma como dato primario sus funciones". Hay varias corrientes funcionales, pero todas tienen en común atender al fin primordial del lenguaje: "la interacción social por medio de la comunicación" (Christopher Butler y otros, Id.: 14).

El funcionalismo se basa en el axioma de que no se puede dominar nada por completo, sea de la naturaleza que sea, mientras no se conozcan los usos -fines o funciones- del objeto que se quiere explicar. El funcionalismo surge de una concepción teleológica del lenguaje, según la cual este es un instrumento u organum y, al mismo tiempo, una actividad que tiene un propósito general, la comunicación, y varias finalidades específicas derivadas de esta; a cada una de ellas se las llama FUNCION (Cfr. gramática funcional). El carácter teleológico del lenguaje fue una de las tesis expuestas en 1929 por el Círculo de Praga en el I Congreso de Filólogos Eslavos. Concretamente, postularon que el análisis linguíístico debía hacerse desde el punto de vista de la función, al ser la lengua un sistema de instrumentos de expresión empleados con un fin.

Las funciones se materializan en cuatro dimensiones operativas del enunciado que son: el nivel fonológico (suprasegmental, preferentemente), sintáctico (central y periférico), semántico (argumental y adjunto) y pragmático (canónico y marcado). Los cuatro niveles son manipulados por el hablante a partir del "control externo de la sintaxis" (vid. supra). La incorporación del plano informativo, como oportunamente señalaran Butler y otros (Id. 28-29), integra el análisis lingüístico "en una teoría más amplia del comportamiento humano: la pragmática o la sociolingüística", incorporando en la descripción al hablante y al oyente. En la actualidad, "nadie discute que la gramática deba incluir en sus descripciones datos pragmáticos". Es la opinión, ampliamente aceptada, de Graciela Reyes (2000: 13).

La identificación de las funciones se rige por el principio de pertinencia, según el cual se consideran relevantes -aclara Salvador Gutiérrez (1997c: 19)- "sólo aquellos aspectos materiales que estén investidos de función"; esto es, entidades linguísticas dotadas de intensión y extensión informativa.

Sintácticamente, los hechos lingüísticos se analizan en su dimensión sintagmática, procurando identificar las relaciones que contraen interna y externamente los funtivos oracionales. A esto, se suma la observación de fenómenos gramaticales de carácter evolutivo, como la gramaticalización, la lexicalización y la transposición. En el eje paradigmático, por otra parte, se deducen las clases de funtivos que son compatibles con los respectivos funtemas, obteniendo el conjunto de recursos disponibles en el sistema. Esta operación analítica cierra el examen sintáctico de la cláusula al elicitar los sintactemas del nexus, es decir, las ranuras funcionales donde una categoría se inviste de función.

Es importante destacar que el análisis sintáctico funcional no se restringe a la representación binaria (verdadero dogma del estructuralismo). Al respecto, Guillermo Rojo y Tomás Jiménez Juliá (1989: 23) defienden la flexibilidad del modelo: "Un análisis funcional coherente y liberado de prejuicios no sólo no tiene por qué ajustarse a una segmentación constantemente binaria sino que, por el contrario, utilizará en un gran número de ocasiones segmentaciones ternarias y superiores".

En el plano semántico, el modelo se aboca a la descripción de las propiedades de los constituyentes léxicos fundamentales: el verbo, encargado de codificar el evento, y el nombre, responsable de instanciar las entidades integradas al evento denotado por el 
signo verbal. También, se describe la estructura argumental de la cláusula a partir de la configuración semántica del lexema verbal, lo que permite distinguir entre componentes valenciales y componentes circunstanciales.

En cuanto al plano pragmático, el análisis funcional determina la expresión sintáctica y léxica de la organización informativa del fenómeno lingüístico. En relación con este punto, Salvador Gutiérrez (1997a: 21) ha señalado a modo de principio que todo enunciado se configura "como respuesta a una pregunta inicial", efectivamente formulada o construida a priori por el emisor. Esta pregunta se materializa en dos niveles informativos: lo que el hablante declara saber (información conocida) y lo que declara no saber y pregunta (información nueva).

Sobre la base de este principio, el análisis funcional incorpora una serie de elementos informativos en la descripción sintáctica. Tal es el caso de: tema(tización) y rema(tización), focalización y atenuación, por citar unos pocos, pero buenos ejemplos. Estas funciones informativas se emplean, en última instancia, como indicadores de predicación pragmática, procedimiento empírico que permite discernir entre enunciados de configuración canónica y enunciados de configuración no canónica.

Esta terminología pragmática es muy rentable en el estudio del orden de constituyentes, en particular, del orden que no depende de las propiedades estructurales de la lengua. Estas últimas instancian una distribución canónica basada en principios como:

\section{- Determinación de la modalidad oracional (modus)}

- Prominencia distribucional de los elementos subordinantes

- Ergatividad/inergatividad verbal

- Flexibilidad posicional de los adjuntos

En condiciones normales, todo uso lingüístico o, mejor aún, todo enunciado lingüístico -unidad inherentemente contextualizada (Graciela Reyes 1996: 13) - es la expresión de una intención comunicativa. Según Catalina Fuentes Rodríguez (1999: 9): "Toda la lengua (sintaxis, semántica y fonética) estaría orientada a la información, a deshacer incertidumbres, a decir algo al destinatario (lo que supondría que el hablante utiliza todos los materiales disponibles a su alcance para llevar esa información)". Se puede apreciar que la transmisión de información es prioritaria: "al hablar -escribe José Portolés (2003: 8)- no pensamos en reproducir literalmente una realidad, sino en conseguir que nuestro interlocutor llegue al enriquecimiento pragmático oportuno".

Se desprende que el estrato informativo no está al mismo nivel que el estrato lingüístico. No es superior ni inferior; es externo y la lengua está al servicio de él. Compárese esta afirmación con lo sostenido hace algún tiempo por Guillermo Rojo (1983: 8990): "Manteniendo los mismos esquemas semántico y sintáctico, una secuencia puede responder a intenciones comunicativas distintas $y$, en consecuencia, presentar estructuras u organizaciones informativas diferentes". Los estratos no están en competencia, sino en complementariedad en el sentido propuesto por Jon Landaburu (2003: 1): lo pragmático tiene que ver con la estrategia informativa, en tanto que lo gramatical se relaciona con la estructuración lógico-gramatical.

La vinculación de ambos niveles es regular, pero no simétrica, como se colige de un caso examinado por Guillermo Rojo (Ibid.): Alfredo paga las bebidas puede ser la respuesta a preguntas tan diversas como: ¿qué paga Alfredo?, ¿qué hace Alfredo? y ¿quién paga las bebidas? El autor demuestra adecuadamente que el enunciado declarativo es compatible con tres esquemas informativos independientes, lo que podría suponer que la extracción enfática de un funtivo sería también compatible con la variedad de mecanismos de relieve disponibles en la lengua. Sin embargo, esto no es así: por ejemplo, la focalización de un OD mediante la construcción de pasiva perifrástica depende de la naturaleza referencial del constituyente nominal. Si el nombre común tiene una referencia abstracta, el SN no puede contraer la función de Sujeto: * Las culpas son pagadas por Juan.

En opinión de José Portolés (2003: 11): "la gramática no es sólo la estructura que permite levantar el edificio de una lengua, es también uno de los ámbitos de una lengua en los que el hablante puede elegir entre distintas opciones para comunicar lo que desea de una manera determinada". Esta precisión resulta apropiada para insistir en la importancia que adquiere en el análisis el "fondo" informativo sobre el que se proyectan las magnitudes lingüísticas. Estas son unidades comunicativas, cuya conversión en objeto de estudio no justifica su descontextualización. Cuando se hace, muchos aspectos (por caso, el orden de palabras) son descritos en forma sesgada (Bello situó las oraciones ecuacionales entre las construcciones anómalas) o parcial (se ha insistido mucho en que las oraciones ecuacionales se ordenan de acuerdo con la posición del tema continuo, soslayando la posibilidad de que el hablante produzca variedades enteramente remáticas).

La asociación entre entidades lingüísticas y propósitos informativos conlleva la copresencia de niveles de diversa organización y funcionamiento, aunque estrechamente relacionados; se trata de los niveles sintáctico, semántico, fonológico, y pragmático, los que se complementan y permiten a todo hablante exponer: "su intención en una organización lingüística que lleva también una organización informativa, a la que se adecua, y en virtud de la cual se organiza la estructura fonológica, sintáctica y semántica del texto" (Catalina Fuentes Rodríguez, Ibid.).

\section{CONFIGURACIÓN INFORMATIVA}

El análisis pragmagramatical -característico de la GF- no presupone la existencia de una gramática pragmática. Se trata más bien de una sintaxis interdisciplinar en la cual, como afirma Angel López García (Id. 21), se admite como principio de trabajo el predominio del valor informativo, el cual, por otra parte, no conlleva que la distribución de palabras esté totalmente condicionada por factores discursivos. Como se sabe, la lengua española estándar fija la posición del Sujeto en las proposiciones interrogativas (¿Dónde estudia Sara? ¿Qué dijo Sandra? ¿Cuándo llega mi hijo?). Esta característica es una propiedad sintáctica del español, independiente, como ha destacado María Luisa Zubizarreta (1999: 4217), de consideraciones discursivas. Aquella es 
intrínseca al funcionamiento de la cláusula, no sometida a ambigüedad como ocurre en el siguiente caso: "Ante una secuencia como La oposición es la que está equivocada, se puede afirmar que se trata de una oración simple atributiva; sin embargo, no es factible agregar que constituya una variante ecuacional, pues, al no poseer un significante específico -también podría ser una oración ecuativa-, la confirmación de aquel valor depende del contexto o entorno informativo" (Pinuer 2000: 154-155).

Establecida esta precisión, sería momento de examinar algunos fenómenos contextuales de gran importancia, comenzando por precisar qué se entiende por función contextual o informativa. Se trata de estados sicológicos o mentales que el hablante comunica en sus discursos; no tienen que ver con la referencia, aunque están estrechamente ligados a ella. Son, como lo ha establecido María Victoria Escandell (1996: 31): “conocimientos, creencias, supuestos, opiniones y sentimientos de un individuo en un momento cualquiera de la interacción verbal".

La concepción de Escandell recoge un axioma preeminente en el ámbito de la lingüística funcional, cual es que lo informativo se manifiesta en la contextualización del fenómeno lingüístico, no antes.

Por su parte, la terminología para designar lo dado y lo nuevo en el mensaje es variada e incluso contradictoria. Generalmente, se opta por la nomenclatura de mayor aceptación, tema y rema, que tiene la ventaja de la productividad derivativa, que destacara Heles Contreras (1978: 21): "Se puede hablar de elementos temáticos y remáticos, de la posibilidad de tematizar o rematizar un constituyente, se puede caracterizar a ciertos elementos como rematizadores, etc.".

La vinculación entre el tema de la oración y el material informativo dado tiene un amplio arraigo en los estudios funcionales hispánicos, a pesar de que Halliday (2004: 93) ha matizado ambos términos: "The Theme is what I, the speaker, choose to take as my point of departure. The Given is what you, the listener, already know about or have accessible to you. Theme + Rheme is speaker-oriented, whereas Given + New is listener-oriented."

El tema o soporte comprende la información conocida (en algún grado) o asumida como tal. Y como precisa José María Gil (2001: 187): "A no ser que haya buenas razones para sugerir lo contrario, el tema es el elemento que se coloca primero o a la izquierda". La posición inicial corresponde a la distribución no marcada, por lo cual la instanciación del tema como Sujeto de la cláusula no es, en rigor, un caso de tematización. Para José Luis Cifuentes (2000: 365) el orden tema-rema es neutro, apreciación que confirma el carácter no marcado de esta configuración distribucional: "el distinto orden de palabras que manifiestan las oraciones refleja una jerarquía de prioridades dependiente de la voluntad comunicativa del hablante, y en la que según el esquema más básico, o neutro, el tema aparece al principio, dándose el rema a continuación".

En el ámbito de una predicación informativa, la ubicación de los constituyentes lingüísticos se subordina a un conjunto de expectativas pragmáticas, entre ellas: el foco, el contraste, la desambiguación y el cumplimiento de las máximas conversacionales (Graciela Reyes 2000: 348). El carácter abierto de estas expectativas confiere una amplia libertad a la acomodación de las unidades discursivas. Sin embargo, la libertad es relativa, pues, como lo ha demostrado Antonio Briz (2001: 79), "responde a una estrategia de comunicación".

Para Graciela Reyes (1985: 570), el tema designa: "información ya establecida en el contexto verbal, presente en el contexto empírico, o presupuesta por hablante y oyente en virtud de los sobreentendidos de la conversación”. Por su parte, el rema o aporte condensa la información nueva para el destinatario, por lo cual, "es lo que realmente informa de algo al receptor [...]" (Rafael Núñez y Enrique del Teso 1996: 95). Un error de cálculo pragmático podría determinar que el tema o el rema sean "objetados" por el destinatario si no coinciden con sus expectativas referenciales. Por ejemplo, si un estudiante comenta en su curso que la profesora postergó una prueba, será noticia (rema) si el resto lo ignoraba. Por el contrario, será información enteramente desconocida, si sus compañeros no se habían enterado de que se había fijado tal prueba (tema).

Tema y rema imponen una estructura binaria del mensaje lingüístico, aun en los casos en que se prescinde del primero, pues como advierte Salvador Gutiérrez (1997a: 23): "en la elipsis la información conocida sigue funcionando". Este carácter binario permite al hablante "polarizar la información de acuerdo con la finalidad de su discurso" (Manuel Casado Velarde 1997: 26).

Graciela Reyes (1985: 577) ha señalado que la lengua española se caracteriza por imbricar el tema con el sujeto y el rema con el predicado:

(1) La política (Tema/Sujeto) se ha convertido en un lucrativo negocio (Rema/Predicado)

(2) El sacerdocio (Tema/Sujeto) no es una profesión (Rema/Predicado)

(1) y (2) poseen un orden canónico o no marcado (María José Rodríguez 1992: 34), mediante el cual la porción no presupuesta o nueva se localiza en el segundo brazo de la estructura, y el conocido o compartido, en el primero; cumpliendo, según Carmen Silva Corvalán (1984: 6), la función de enlace textual.

La ubicación inicial del tema en función sintáctica de Sujeto selecciona un constituyente discursivo como tema o tópico (Manuel Casado Velarde, Id.: 29) y lo instancia canónicamente. Por su parte, la tematización marcada o de predicación pragmática se realiza a través de otros recursos, que identificamos a continuación sobre la base de lo expuesto en un trabajo anterior (Pinuer 2000: 157-158):

- Dislocación a la izquierda o a la derecha, con eventual reforzamiento pronominal (clíticos): A la economía (tema) le falta mayor dinamismo (rema).

- Uso de preposiciones o locuciones preposicionales que revisten marca temática: Acerca de su accidente (tema) te puedo decir que...(rema).

- Condensación estructural con reforzamiento prosódico: ¡A tu casa! (tema), no volveré a entrar (rema).

- Inserción de un verbo existencial (ser, haber) o una construcción presentativa (esto es, eso de): Esto de ser la otra (tema), no me gusta nada (rema). 
- Declaración explícita del tema: Hablando de tu padre (tema), ¿cómo sigue? (rema).

Las diferentes estrategias de tematización coinciden en extrapolar la entidad tematizada, haciendo evidente la flexibilidad distribucional que caracteriza al español, fenómeno que contrasta con la independencia informativa de cada configuración.

La dislocación puede conllevar, además, la focalización de un constituyente oracional. Para entender esto, se debe tener en cuenta que la oración española de modalidad declarativa tiene un orden estructural no marcado que es $(\mathrm{S})+\mathrm{V}+\mathrm{O}(\mathrm{Julio}$ Calvo Pérez 2000: 350), característico de las construcciones con dos argumentos (Carmen Silva Corvalán, Id:: 1). Este patrón alterna con otras distribuciones que tienen la misma neutralidad informativa $-\mathrm{V}+(\mathrm{S})+\mathrm{O}, \mathrm{V}+\mathrm{O}+(\mathrm{S})-$, pero no el mismo nivel de aparición, ya que predomina claramente el primer patrón, lo que sería "resultado de la tendencia más general que sitúa los núcleos delante de los complementos" (José Luis Cifuentes, Id.: 359).

La preeminencia de ciertas configuraciones no es, en otro sentido, evidencia de estructuras automatizadas. Al respecto, Graciela Reyes (1996: 30) alerta en el sentido de que "es muy difícil (y quizá teóricamente errado) estudiar el lenguaje como un sistema de reglas autónomo, es decir, independiente del uso". Al ser el español una lengua de sujeto pro-drop (sujeto caído), por lo general, la introducción de un sujeto léxico se justifica pragmáticamente. De esta manera lo entienden Antonio Briz et al. (2000: 230): "la simple aparición del mismo será en la mayor parte de los casos una forma de realce, bien porque aparezca (si lo normal o más frecuente es que no lo haga), o bien porque aparezca fuera de la posición primera o neutra". Como se puede apreciar, aun en los casos de mayor prominencia distribucional (caso del sujeto preverbal en español) sería posible introducir justificaciones pragmáticas.

En suma, la distribución de constituyentes depende fundamentalmente de factores pragmáticos, como la escisión entre lo dado y lo nuevo, y el relieve informativo. De esta forma, el orden opera como un recurso eficiente de complementación de la carga informativa de la oración, naturalmente, en la medida que "las presuposiciones y los valores compartidos por los interlocutores funcionen de modo adecuado" (Milagros Fernández Pérez 1999: 127).

La modificación del orden no marcado evidencia una intención comunicativa que, la mayoría de las veces, se relaciona con la asignación de prominencia informativa. Sobre el particular, Cifuentes (Id. 365) sostiene que "al anteponer al inicio de la oración un elemento que no tendría esa disposición según el orden neutro tema-rema, se realza el papel del elemento desplazado". Este desplazamiento representa una ruptura o fractura del patrón canónico, lo que respalda el empleo del término dislocación.

Los estudios, en general, se han centrado en la dislocación a la izquierda (UN KILO DE HEROINA detectó la policía en estómago de burrero peruano), pero el mismo efecto se logra mediante una extrapolación a la posición final absoluta de la cláusula: así es LA DELINCUENCIA. Esta interpretación, no obstante, es probabilística, pues esa posición también podría indicar la tematización del SN; sin contexto, el enunciado es informativamente ambiguo. En la lengua oral, esta polisemia informativa es neutralizada por el acento de intensidad, que discrimina la magnitud ponderada.

Ciertos estudios (como los realizados por Antonio Briz y el Grupo Val.Es.Co), plantean la posibilidad de que la dislocación con añadidos a izquierda ("o que se le había perdido a la chica") y derecha ("lo han hecho fijo a mi marido"), tenga efectos exclusivos de tematización. En concreto, estos investigadores puntualizan que (2000: 234): "Las predicaciones deben guardar una especie de coherencia interna, de ahí que el hablante utilice estos añadidos a izquierda o derecha (dislocaciones) con el fin de precisar su discurso, hacer una aclaración, etc.".

Estas proformas generan una coindizacion interna que, en efecto, fortalece la referencialidad de la cláusula y con ello el piso informativo del intercambio verbal (tema). Sin embargo, su carácter elusible las convierten en unidades potencialmente focalizadoras, al menos desde una perspectiva teórica.

\section{DISPOSITIVOS SINTÁCTICOS DE FOCALIZACIÓN}

El foco o relieve se ha convertido en una noción muy influyente en gran parte de los planteamientos funcionalistas de la lingüística actual. Para Catalina Fuentes Rodríguez (Id. 8), focalizar es: "destacar una información dentro de la oración, un segmento (o varios) que tiene más peso dentro de todo el grupo". De esta forma, el foco es la porción de discurso que posee el valor informativo más alto. Su función comunicativa, precisa Salvador Gutiérrez (1997a: 34): "suele ser la de llamar la atención del receptor con el fin de vencer en éste una predisposición contraria o simplemente de subrayar su importancia en el proceso informativo en que se hallan inmersos". Julio Calvo Pérez (Id. 354) agrega que la presencia de un foco subordina el orden de palabras a "la exigencia de realce expresivo".

El foco es un fenómeno que necesariamente debe ser analizado en la lengua oral y escrita, pues su finalidad informativa lo sitúa simultáneamente en los dos planos. Al respecto, conviene tener presente la tesis de Antonio Briz Gómez (2001: 19) según la cual: "junto a los modos de expresión extremos, lo oral y lo escrito, se encuentran manifestaciones o reflejos diversos de lo oral en lo escrito [...] y de lo escrito en lo oral [...]". Para reforzar esta tesis, el propio Briz (Id. 20) destaca que los géneros periodísticos y literarios actuales "imitan en algún aspecto el registro coloquial con el fin de enriquecer expresivamente el mensaje, la narración, los diálogos".

La focalización se justifica comunicativamente al existir una función pragmática opuesta que es la atenuación, estrategia de cortesía por medio de la cual "se atenúa la fuerza ilocutiva de los actos de habla" (Juana Puga 1997: 35), con lo que el hablante minora sus propias cualidades o bien los defectos del interlocutor (Ibid.). Por el contrario, la prominencia informativa acciona los recursos oportunos, que en ciertos contextos (como el refutativo) llegan a superponerse como en el siguiente caso descrito por Salvador Gutiérrez (2002: 78): “¡PRECISAMENTE PORQUE ES COMPRENSIVA abusas de ella!

En esta oración causal concurren simultáneamente: prominencia prosódica (modus exclamativo), dislocación clausal (porque es comprensiva) y refuerzo adverbial (precisamente).

A continuación, se examinarán someramente tres casos o dispositivos de focalización para ilustrar el funcionamiento de una 
metodología de análisis sintáctico de orientación funcional.

1. PASIVA ANALITICA. En una interpretación atributiva funcional, las oraciones adscriptivas de contenido pasivo operan como un recurso sintáctico de focalización, el cual permite subrayar un OD mediante su reinterpretación como sujeto léxico de una oración pasiva perifrástica: La apacible vida de los habitantes de esta idílica isla es alterada cada verano con la llegada de miles de turistas (Cfr. La llegada de miles de turistas cada verano altera la apacible vida de los habitantes de esta idílica isla).

La anteposición del OD es subsidiada por una modificación verbal, que consiste en la conversión del verbo simple en una perífrasis semigramaticalizada o en vías de gramaticalización. Carlos Subirats (2001: 13) destaca otro aspecto argumental muy importante: "la pasivización permite aglutinar el nombre predicativo y sus segundos argumentos, que [...] pasan a ocupar una posición inicial a la izquierda del predicado en la oración derivada”.

Según destacáramos en otro momento (2000), José Manuel González Calvo (1991: 196; 1992: 108-109) atribuye al carácter enfático de estas construcciones su escasa aparición. En concreto, señala que: "las estructuras pasivas no son frecuentes en nuestra lengua, ya que requieren contextos pragmáticos y gramaticales de especial encarecimiento o relieve [...]”. Convendría precisar que esta constatación describe más la situación de la lengua oral que de la lengua escrita; en esta última y sobre todo en registros especializados como el discurso periodístico, estas estructuras poseen una importante visibilidad.

Sintácticamente, las pasivas analíticas se distinguen por tener la propiedad de expresar como Sujeto un argumento que, por lo general, se exterioriza como OD. Al respecto, precisa Amaya Mendikoetxea (1999: 1636): "lo que caracteriza a las oraciones pasivas es que tienen como sujeto gramatical (o sintáctico) un sintagma nominal que se interpreta como el objeto nocional (o semántico) de la acción denotada por el verbo".

2. CONSTRUCCIONES ECUACIONALES O ESCINDIDAS. Se trata de una variedad de oración seudoatributiva que permite focalizar complementos argumentales, no argumentales y cláusulas simples o complejas. Su denominación, que debemos a Emilio Alarcos (1978: 232), alterna con los de fórmula perifrástica de relativo (Salvador Fernández Ramírez 1951: 161-162, 176), perífrasis de relativo (Juan Carlos Moreno Cabrera 1983: 456) y oración hendida (María Luisa Rivero 1971) o escindida, entre otras posibilidades. Estas últimas denominaciones corresponden a la traducción del término cleft e implican una identidad entre las estructuras escindidas y construcciones equivalentes del inglés, semejanza que ha sido rechazada por varios gramáticos, entre ellos Salvador Gutiérrez (1986: 50). En principio, y tal como se precisa en un trabajo sobre el tema (Pinuer 2002: 130-131), no existe una correspondencia formal plena, pero desde un punto funcional e interactivo se aprecia el mismo efecto focalizador.

Si bien la focalización ecuacional es un fenómeno que se desarrolla en la dimensión sintáctica de la lengua, su funcionamiento, como es de esperar, no está supeditado sólo a factores sintagmáticos. En efecto, la ponderación de los complementos argumentales del verbo se subordina a ciertas exigencias predicativas, una de las cuales es que no se puede resaltar "el sujeto y el verbo dejando fuera el objeto" (Escandell 2004: 142).

Según se ha planteado, las construcciones escindidas segregan una función primaria, generando una correlación anafórica con la versión ausente no enfatizada:

a.

El sobreendeudamiento agobia a los chilenos

El sobreendeudamiento es lo que agobia a los chilenos

b.

Jueza otorgó excarcelación a peligroso narcotraficante

Fue a peligroso narcotraficante a quien jueza otorgó excarcelación

La ejemplificación nos permite sostener que todo enunciado ecuacional se vincula anafóricamente con una versión no ecuacional o no enfatizada (Margarita Porroche 1990: 94), en el sentido de que en el primero hay un constituyente extraído del segundo y dotado de relieve sintáctico, que resulta: "compatible con la relevancia pragmática que desea adjudicarle el hablante" (Mercedes Sedano 1996: 126).

Estudios sintácticos cognitivos han acentuado dos propiedades de estas oraciones, que se resumen a continuación, siguiendo la formulación de María Fernández Lagunilla y Alberto Anula Rebollo (1995: 328-329). La primera se refiere a la existencia de un elemento marcado con énfasis o foco, en tanto que la segunda propiedad se relaciona con el sentido especificativo o identificativo de la predicación que se establece entre las dos magnitudes enlazadas por el verbo copulativo, el que actúa como un conector pleno gracias a su "plena desemantización léxica o referencial" (Pinuer 1999).

Juan Carlos Moreno Cabrera (1999: 4248-4250) ha destacado la bidireccionalidad que singulariza la relación entre decurso focalizado y decurso no enfatizado, a partir de la conversión en PdR [Perífrasis de Relativo] de una oración neutra y, en sentido inverso, la conversión de una PdR en su correspondiente estructura no perifrástica. El primer proceso se denomina 'expansión perifrástica' y el segundo, 'contracción de la perífrasis'.

Ofelia Kovacci (1991: 40) señala que entre ambos decursos existe una: “oposición paradigmática sintáctico-semántica”, basada en la subcategorización [+/- énfasis]. Esta característica explica que la relación entre secuencia no focalizada y focalizada evidencie similitudes y contrastes. En relación con esto último, Jenaro Ortega Olivares (1988: 209) precisa que: "la expresión enfática y su correspondiente neutra son equivalentes en cierto sentido: describen las mismas cosas (Luis estudia chino = El que estudia chino es Luis), pero difieren en los aspectos interactivos y, especialmente, textual". En suma, lo que se quiere destacar es que una oración neutra y su equivalente hendida denotan el mismo estado referencial, pero no comunican idéntico estado informativo.

En la interpretación de Andrés Bello (1981), los segmentos ecuacionales constituían estructuras anómalas, considerando la 
imposibilidad de describirlas mediante el aparato teórico tradicional. Por su parte, Julio Calvo Pérez (Ibid.) las ha considerado "estructuras desviantes en el plano sintáctico". Ambas posiciones no son correctas, aun cuando deba admitirse que en algunos casos estas construcciones resultan algo desusadas y/o pragmáticamente extrañas: Es mala persona lo que es Juan. José Portolés (2004: 35) lo calificaría como un enunciado costoso de comprender.

En este punto cabe destacar, como lo ha hecho Carlos Subirats, que la gramaticalidad es un fenómeno que debe determinarse en el acto comunicativo. Según este autor (Id. 18), "la gramaticalidad no se puede considerar como una propiedad inherente de determinados discursos, sino como una indicación [...] de la posibilidad o imposibilidad de que dichos discursos puedan ser utilizados o no en un contexto comunicativo real para vehicular significados". Esto hace necesario, como advierte María Victoria Escandell (2004: 19), distinguir entre gramaticalidad e interpretabilidad.

3. CONSTRUCCIONES ECUANDICIONALES. Son construcciones del tipo: Si algo le molesta es la mentira. Han sido cuidadosamente estudiadas por Salvador Gutiérrez, quien ha confirmado que la diferencia más relevante entre éstas y las oraciones ecuacionales radica en el constituyente no focalizado, el cual: "en las ecuacionales venía encabezado por un relativo, mientras que en [aquellas] aparece un segmento de naturaleza hipotética" (1997b: 555). La cláusula condicional o hipotética tiene una posición inicial fija.

Las ecuandicionales tienen varios aspectos polémicos uno de los cuales tiene que ver con su clasificación estructural. Tienen forma atributiva, pero no existen pruebas sintácticas para demostrar qué segmento funciona como Sujeto y cuál, como Atributo. Salvador Gutiérrez ha llegado a decir que en esta y otras estructuras análogas (las oraciones escindidas) no es posible reconocer funciones sintácticas primarias.

Otro asunto discutible es la relación existente entre ecuacionales y ecuandicionales, tanto a nivel de configuración como a nivel de rentabilidad informativa. Aparentemente, estas últimas se limitan a focalizar constituyentes de estructuras complejas, lo que habría que observar en un corpus amplio y realístico.

En un estudio comparativo entre ambas formas sintácticas de focalización (Pinuer 2005), se comprobó en una muestra de español escrito, que las oraciones ecuandicionales se emplean casi en la totalidad de los casos para ponderar circunstantes causales (trabaja porque no tiene alternativa $\rightarrow$ si trabaja es PORQUE NO TIENE ALTERNATIVA). Esto determina que, frente a las construcciones ecuacionales, tengan un bajo índice de aparición, pues las estructuras escindidas se emplean para destacar todas las funciones primarias.

Es importante dar a conocer que en los trabajos citados sobre estructuras ecuacionales y ecuandicionales, el material de estudio estuvo constituido por oraciones simples, aunque existen manifestaciones hipotácticas. Tal vez, la diferencia de nivel sintáctico no tenga incidencia en su naturaleza y funcionamiento, pero esto se debe determinar empíricamente.

Tampoco se han tenido en cuenta contextos interrogativos y exhortativos que, frente a los declarativos, "no se contraponen el uno al otro, si no [sic] más bien expresan variantes de una única estrategia discursiva" -acota Livia Gaudino-Falleger (2000: 9)- .

\section{CONCLUSIÓN}

A pesar de que el funcionalismo (sintáctico) tiene un desarrollo doctrinario y programático reciente, ha alcanzado un intenso nivel de discusión del cual se han construido de manera sólida las bases teóricas y los procedimientos heurísticos. No cabe duda de que sus principales impulsores han sabido nutrirse de la rica tradición estructuralista así como de los desarrollos contemporáneos de la lingüística, particularmente del generativismo y de la pragmática. Con ello, las diversas escuelas funcionales han abierto nuevas rutas para la investigación del fenómeno lingüístico, las cuales tienen que ver con la codificación de la intención comunicativa del hablante, la figura del destinatario y la organización informativa de los mensajes.

$\mathrm{Si}$ bien se pueden encontrar diferencias importantes de una escuela a otra (por caso, la incorporación formal del plano pragmático), se coincide en proponer métodos flexibles, igualmente válidos para la descripción del registro formal y coloquial. Lo anterior ha permitido explicar con igual rigor enunciados de orden canónico y enunciados de orden pragmático. Por largo tiempo, estos últimos quedaron al margen de examen gramatical, alegándose su carácter anómalo o desviante, cuando en realidad lo anómalo era la aplicación de una metodología inadecuada, caracterizada, en general, por el binarismo absoluto y el sintacticismo extremo.

Llama la atención que nuestra gramática haya operado como si el español fuera una lengua de orden rígido o, al menos, una lengua sin distribución distintiva. Cuando se ha actuado así, muchos fenómenos han quedado parcialmente descritos, como es el caso de la posición de los complementos argumentales en la cláusula, problema que comenzó a explicarse una vez que en el análisis se incluyó la función informativa de tematización.

Los enunciados de configuración pragmática no pudieron ser descritos adecuadamente, debido a la aplicación de metodologías de alto formalismo estructural. Por cierto que todo enunciado tiene organización informativa y estructura gramatical, pero los de configuración pragmática están subordinados a las necesidades informativas del hablante y no a las propiedades estructurales de la lengua, con lo cual, es frecuente que se recurra a construcciones que se apartan de la fisonomía canónica. En otro caso, la producción de oraciones elaboradas bajo este principio rector ha llegado a adquirir una función no etimológica.

En la situación anterior se encuentran las oraciones pasivas analíticas o dinámicas, cuyo análisis pragmagramatical vino a corroborar, por ejemplo, que su bajo índice de aparición no se debía a su complejidad derivativa, sino a exigencias de contexto de encarecimiento o relieve, dada su naturaleza focalizadora y tematizadora (en otros casos).

Las construcciones ecuacionales y ecuandicionales son aún ejemplos más ilustrativos (que el de las pasivas perifrásticas) de la urgencia que se tenía de contar con un análisis gramatical que no excluyera lo informativo y lo semántico. En efecto, la imposibilidad de realizar en ellas el análisis sintáctico tradicional las condenó al "estigma" de las estructuras anómalas o 
desviantes (como ocurrió con las construcciones ecuacionales) o al lugar enigmático conocido como "variedad de" (caso de las ecuandicionales). Como se vio, ambas construcciones son gramaticales, tienen identidad formal y una función pragmática específica.

\section{OBRAS CITADAS}

Alarcos, Emilio. 1978. Estudios de gramática funcional del español. Madrid: Gredos.

Bello, Andrés. 1981. Gramática de la lengua castellana. Vol. 2. Tenerife: Instituto Universitario Andrés Bello.

Briz Gómez, Antonio. 2001. El español coloquial en la conversación. Esbozo de pragmagramática. Barcelona: Ariel.

Briz Gómez, Antonio y Grupo Val.Es.Co. 2000. ¿Cómo se comenta un texto coloquial? Barcelona: Ariel.

Butler, Christopher et al. 1999. Nuevas perspectivas en gramática funcional. Barcelona: Ariel.

Calvo Pérez, Julio. 2000. "El orden de los elementos". Introducción a la lingüística española. Dir. Manuel Alvar. Madrid: Barcelona. 345358.

Casado Velarde, Manuel. 1997. Introducción a la gramática del texto del español. Madrid: Arco Libros.

Cifuentes Honrubia, José Luis. 2000. “El orden de palabras en la oración”. Introducción a la lingüística española. Dir. Manuel Alvar. Madrid: Barcelona. 8-22.

Contreras, Heles. 1978. El orden de palabras en español. Madrid: Cátedra.

Dik, S. C. 1978. Functional Grammar. Amsterdam: North Holland.

Escandell Vidal, M. Victoria. 2004. Fundamentos de semántica composicional. Barcelona: Ariel. 1996. Introducción a la pragmática. Barcelona: Editorial Ariel.

Fernández Lagunilla, María y Alberto Anula Rebollo. 1995. Sintaxis y Cognición. Madrid: Síntesis.

Fernández Pérez, Milagro. 1999. Introducción a la lingüística. Barcelona: Editorial Ariel.

Fernández Ramírez, Salvador. 1951. Gramática española: El pronombre. Madrid: Arco Libros.

Fuentes Rodríguez, Catalina. 1999. La organización informativa del texto. Madrid: Arco Libros.

Gaudino-Fallegger, Livia. 2000. Notas sobre la sintaxis de los titulares de las revistas femeninas. En línea: http://www. ucm.es/info/circulo/n²/gaudino-fallegger.htm [Consulta: 7/05/2004]

Gil, José María. 2001. Introducción a las teorías lingüísticas del siglo XX. Buenos Aires: Melusina.

Givón, T. 1995. Functionalism and Grammar. Amsterdam: John Bejamins.

González Calvo, José Manuel. 1992. "Notas sobre las estructuras llamadas pasivas con ser en español (II)”. Anuario de Estudios Filológicos XIV: 183-198.

González Calvo, José Manuel. 1991. "Notas sobre las estructuras llamadas pasivas con ser en español (I)”. Anuario de Estudios Filológicos XV: 107-13.

Gutiérrez Ordóñez, Salvador. 2002. Forma y sentido en sintaxis. Madrid: Arco Libros.

—. 1997a. Temas, remas, focos, tópicos y comentarios. Madrid: Arco Libros.

1997b. La oración y sus funciones. Madrid: Arco Libros.

1997c. Principios de sintaxis funcional. Madrid: Arco Libros.

1986. Variaciones sobre la atribución. León: Ediciones Universidad de León.

Halliday, M. A. K. 2005. On Grammar. United States: Continuum.

2004. An Introduction to Functional Grammar. London: Edward Arnold.

Hernández Alonso, César. 1996. Gramática funcional del español. Madrid: Gredos.

Kovacci, Ofelia. 1991. "Sobre la estructura de la forma de relieve con ser y proposición relativa". Voz y Letra. Revista de Filología II, 1: 3949.

Kuno, S. 1980. "Functional Syntax". Moravcsik y Wirth, eds.: 117-135.

Landaburu, Jon. 2003. Entre sintaxis y pragmática: El surgimiento de una estructura predicativa. En línea: http://www.utexas.edu/cola/llilas/centers/cilla/landaburu-article.doc+sintaxis+y+pragm\%C3\%A1tica\&hl=es\&ie=UTF-8 [Consulta: $12 / 05 / 2004]$

López García, Angel. 2000. "Teoría Gramatical”. Introducción a la lingüística española. Dir. Manuel Alvar. Madrid: Barcelona. 8-22.

Mendikoetxea, Amaya. 1999. "Construcciones con se: Medias, pasivas e impersonales”. Gramática descriptiva de la lengua española. Eds. Ignacio Bosque y Violeta Demonte . Vol. 2. Madrid: Espasa Calpe. 1630-1722.

Moreno Cabrera, Juan Carlos. 1999. "Las funciones informativas: Las perífrasis de relativo y otras construcciones perifrásticas". Gramática descriptiva de la lengua española. Eds. Ignacio Bosque y Violeta Demonte. Vol. 3. Madrid: Espasa Calpe. 4245-4302.

. 1983. "Las perífrasis de relativo". Serta Philologica F. Lázaro Carreter, I. Estudios de Lingüística y Lengua Literaria. Madrid: Cátedra. 455-467.

Núñez, Rafael y Del Teso, Enrique. 1996. Semántica y pragmática del texto común. Madrid: Cátedra.

Ortega Olivares, Jenaro. 1988. "Observaciones sobre las fórmulas perifrásticas de relativo". Studia Litteraria atque Lingüística [Universidad de Granada]. 185-210.

Pinuer Rodríguez, Claudio. 2005. "Relieve sintáctico en el español escrito de Chile: Las construcciones ecuacionales y ecuandicionales". SIGNOS 38(57): 75-88.

—. 2002. "Sintaxis y pragmática de la oración ecuacional". RLA 40: 129-145.

—. 2000. "Estructura informativa y atribución". ONOMAZEIN 5: 153-166. 
1999. "Extensión y diferenciación de la serie verbal atributiva en español". RLA 37: 95-106.

Porroche, Margarita. 1990. Aspectos de la atribución. Zaragoza: Libros Pórtico.

Portolés, José. 2004. Pragmática para hispanistas. Madrid: Editorial Síntesis.

—. 2003. Pragmática y sintaxis. En línea: http//www.espaciologopedico.com/articulos2asp?id_articulo=582 [Consulta: 10/04/2004]

Puga, Juana. 1997. La atenuación en el castellano de Chile. Un enfoque pragmalingüístico. Valencia: Tirant lo Blanch.

Reyes, Graciela. 2000. "Pragmática y descripción gramatical”. Introducción a la lingüística española. Dir. Manuel Alvar. Madrid: Barcelona 433-443.

1996. El abecé de la pragmática. Madrid: Arco Libros.

. 1985. "Orden de palabras y valor informativo en español”. Philologica Hispaniensia, in Honorem Manuel Alvar, II. Lingüística. Madrid: Gredos. 567-588.

Rivero, María Luisa. 1971. "Una restricción de la estructura superficial sobre la negación en español”. Los fundamentos de la gramática transformacional. Comp. Heles Contreras. México: Siglo XXI. 91-134.

Rodríguez Espiñeira, María José. 1992. "Sobre la codificación informativa de las cláusulas con predicativo en español". Revue Romane [Universidad de Copenhague]. 27,1: 30-60.

Rojo, Guillermo y Jiménez Juliá, Tomás. 1989. Fundamentos del análisis sintáctico funcional. Santiago de Compostella: Universidad de Santiago de Compostella.

Rojo, Guillermo. 1983. Aspectos básicos de sintaxis funcional. Málaga: Librería Agora.

Sedano, Mercedes. 1996. "Estructura y forma de las hendidas en cinco lenguas románicas: tensión entre economía y claridad". Hispanic Linguistics 8,1: 123-153.

Silva Corvalán, Carmen. 1984. “Topicalización y pragmática en español”. Revista Española de Lingüística 14: 1-19.

Subirats Rüggeberg, Carlos. 2001. Introducción a la sintaxis léxica. Madrid: Iberoamericana.

Zubizarreta, María Luisa. 1999. "Las funciones informativas: Tema y foco". Gramática descriptiva de la lengua española. Vol. 3. Eds. Ignacio Bosque y Violeta Demonte. Madrid: Espasa-Calpe. 4215-4246. 